\title{
LET'S TALK FOOD: ELEMENTARY SCHOOL STUDENTS' PERCEPTIONS OF SCHOOL AND HOME FOOD ENVIRONMENT AND THE IMPACT OF THE HARVEST OF THE MONTH PROGRAM ON THEIR DIETARY ATTITUDES AND BEHAVIORS
}

\author{
Amanda Margolin, Keiko Goto, Cindy Wolff, and Stephanie Bianco
}

\begin{abstract}
This study aimed to further knowledge about elementary school students' views on food environment, and the effects of the Harvest of the Month (HOTM) program on their dietary attitudes and behaviors. Three focus groups were conducted with a total of 24 fourth, fifth, and sixth grade students from low-income schools in northern California who received the National School Lunch Program and HOTM during the school year. Focus groups were tape-recorded, transcribed, and coded for specific themes. Following the intervention, participants expressed a desire for more healthy food options in the school cafeteria and wanted to receive more school and family support for healthy eating. The HOTM program created a positive environment that appeared to influence their dietary attitudes and behaviors, peer and family perceptions of healthy eating, and participants' attitudes toward their schools. Specifically, cooking demonstrations, tasting activities, and take-home recipes provided them with a means to share with their parents what they had learned about fruits and vegetables. School food policy interventions may become more effective if they are combined with interventions based on nutrition education. Future research should focus on exploring effective and synergistic ways of implementing both types of interventions among children.
\end{abstract}

Keywords: focus groups, primary schools, nutrition interventions

Amanda Margolin MS is a Pediatric Dietitian at Providence Pediatric Neurodevelopment Institute, 9205 SW Barnes Rd, Portland, OR 97225, USA. Email: ablairg@ gmail.com

Keiko Goto PhD (the corresponding author) is the Assistant Director of Research and Evaluation, Center for Healthy Communities, and Professor and Graduate Coordinator, Department of Nutrition and Food Sciences, California State University, Chico, CA 95929, USA. Email: kgoto@csuchico.edu

Cindy Wolff PhD is the Executive Director, Center for Healthy Communities, and a Professor in the Department of Nutrition and Food Sciences (NFSC), California State University, Chico, CA 95929. Email: cwolff@csuchico.edu

Stephanie Bianco MS is the Associate Director, Center for Healthy Communities, and an Associate Professor in the Department of Nutrition and Food Sciences, California State University, Chico, CA 95929, USA. Email: sbianco@ csuchico.edu 
International Journal of Child, Youth and Family Studies (2017) 8(3-4): 154-167

Childhood overweight and obesity have become global public health concerns since overweight and obese children are a growing group at risk for the same health complications, such as heart disease, high cholesterol, high blood pressure, and type 2 diabetes, as overweight adults (Pan, Blanck, Sherry, Dalenius, \& Grummer-Strawn, 2012). The global prevalence of overweight and obesity for children and adolescents (ages 2 to 19 years) rose by $47.1 \%$ from 1980 to 2013 (Ng et al., 2014). The United States has one of the highest prevalence rates in the world (Ng et al., 2014). The prevalence of obesity among U.S. children and adolescents was $17 \%$ in 2011 to 2014 (Ogden, Carroll, Fryar, \& Flegal, 2015).

In the United States children spend, on average, over six hours each day at school. There they are exposed to various levels of physical activity as well as many food and beverage choices. Thirty million children in the United States consume at least one meal at school each day, in addition to snacks and other supplementary foods, through the National School Lunch Program (NSLP) and the National Breakfast Program (NBP). These programs make important contributions to students' daily overall dietary intake, especially for children with low socioeconomic status who experience food insecurity at home, many of whom are of minority ethnicity. Therefore, the foods children receive at school strongly impact their overall diet (Clark \& Fox, 2009; Hussar \& Bailey, 2009).

In the United States, a social ecological model was developed by McLeroy, Bibeau, Steckler, and Glanz (1988) to address both individual and social environmental factors for health promotion interventions. It focuses on the importance of interventions directed at changing interpersonal, organizational, community, and public policy factors that affect healthy and unhealthy behaviors (McLeroy et al., 1988). This model has been proposed as a framework for dietary interventions, specifically for nutrition strategies aimed at promoting the adoption of healthy eating behaviors in the United States (Story, Kaphingst, Robinson-O'Brien, \& Glanz, 2008). Individual behavior change can be achieved by addressing the environmental context and conditions in which people live and make choices (Story et al., 2008). Thus, the social ecological model is useful for conceptualizing the many food environments and conditions that influence individual food choices, as well as developing environmental and policy interventions addressing population-wide improvements in eating (Story et al., 2008).

Previous research has identified that theory-driven, behavioral educational strategies are a necessary element of successful school-based intervention programs across the globe (PérezRodrigo \& Aranceta, 2001). Specifically, multicomponent school-based intervention programs have been implemented to promote better nutrition and prevent obesity among children and adolescents (Chen et al., 2014). Past research has shown that such programs with farm-to-schoolcentered curricula are effective at increasing fruit and vegetable consumption among children (Goto, Wolff, Frigaard, \& Bianco-Simeral, 2012; Graham, Feenstra, Evans, \& Zidenberg-Cherr, 2004; Heim, Stang, \& Ireland, 2009; Nicklas, Johnson, Myers, Farris, \& Cunningham, 1998; Perry 
et al., 1998). Children's food perceptions, the cafeteria environment, and their eating habits determine their food choices, and encouraging children to taste and develop a preference for fruits and vegetables may increase their intake of healthy foods (Shannon, Story, Fulkerson, \& French, 2002; McKinley et al., 2005). Despite the strong evidence from those quantitative studies supporting the use of such programs, there have been few evaluations using qualitative methods to identify possible factors that may better explain the impact of programs on dietary behaviors of children. The use of qualitative research for the interpretive enrichment of quantitative studies, as well as for the development of quantitative studies, has proven to be fruitful (Béhague, Gonçalves, \& Victora, 2008). Considering the complexity of the environmental contexts and conditions in which children make choices, qualitative research may contribute to the effective development of school-based nutrition interventions for student dietary behavioral changes.

The Harvest of the Month (HOTM) program, funded by the United States Department of Agriculture, is a multicomponent school-based nutrition program targeting youth in low-income schools. Using the social ecological model, the HOTM program in the study area included five key monthly elements aimed at addressing environmental and personal factors associated with healthy eating: educator newsletters, family newsletters, Farmers of the Month (FOTM) newsletters, classroom workbooks, and cooking demonstrations (California Department of Public Health, 2016). Each element was developed using the social ecological model as a framework and is intended for implementation in areas where nutrition education can make the biggest impact classrooms, cafeterias, homes, and communities. The current study qualitatively examined the perceptions of elementary school students regarding the foods served in the cafeteria, barriers to healthy eating, and their perceptions of the impact of the HOTM program on their dietary attitudes and behaviors. The authors aimed to gain an insight into factors that influence the dietary behavior of children and adolescents, as well as to evaluate the perceived impact of the HOTM program on knowledge, attitudes, and behaviors associated with those identified factors.

\section{Methods}

\section{Study Participants}

The study population included fourth, fifth, and sixth grade male and female students from three low-income elementary schools in northern California that received the NSLP and the HOTM interventions during the school year. Informed consent was obtained from the parents of participants. A convenience sample of 24 students from three schools (eight from each) participated in the study, with 50\% boys and 50\% girls from each school. This study was approved by the Human Subjects Research Committee at California State Univdersity, Chico.

\section{Focus Groups}

Focus groups were used in order to provide a rich understanding of student perceptions of the foods served in the cafeteria, barriers to healthy eating, and the impact of the HOTM program on their dietary attitudes and behaviors. The focus group technique allows more in-depth 
exploration of issues relevant to children, regardless of their literacy skills, than less interactive data collection tools such as surveys (McKinley et al., 2005). A focus group guide was developed to explore fruit and vegetable consumption among children both inside and outside the school environment and how the HOTM program might have impacted student dietary behaviors. The focus group guide consisted of questions regarding students' (a) beliefs and practices regarding the overall school lunch and the foods and beverages offered; (b) views about the HOTM program, fruits and vegetables, and knowledge obtained from the curriculum; and (c) values implemented in the home environment, specifically regarding fruits and vegetables.

Focus groups were held at on-campus locations such as classrooms or libraries. The focus group guide was used to direct the discussion; where the researchers thought it advisable, supplementary probing questions were added in order to ensure thorough responses. To maintain the attentiveness and interest of the participants, each session was limited to approximately 45 minutes. All three focus groups followed the same format. Prior to each focus group session, a brief activity - the naming of favorite fruits and vegetables — was used to build rapport among participants and trust in the facilitator. Trained research staff served as facilitators, audio-recorders, and note-takers for the three focus group sessions.

\section{Data Analysis}

Thematic analysis, a systematic approach for qualitative data analysis (Mills, Durepos, \& Wiebe, 2010), was used to analyze the focus group data. Two trained researchers (first and fourth authors) analyzed data independently. Identified themes and subthemes were then carefully reviewed by all authors in order to make sure that all responses were dealt with even-handedly and that one participant's response was not privileged over another's (Pilnick \& Swift, 2011). The themes and subthemes were further organized and compared across each of the three focus groups. For each category or overarching theme identified, summary statements were written and quotes were extracted to further illustrate the themes and subthemes in order to convey the overall participant perspective.

\section{Results}

The themes identified from the focus groups were divided into three key categories: (a) student views of food items in the school cafeteria; (b) peer and family influences on food behaviors; and, (c) the school food environment. Study participants also discussed their perceptions of the impact of the HOTM program on these identified categories.

\section{Student Views of Food Items in the School Cafeteria}

Availability of fruits and vegetables: Students were asked to describe their perspectives on food items available to them during school lunch. All participants felt positive about fruits and vegetables, were able to describe and name their favorite fruits and vegetables, and also indicated the desire for more fruits and vegetables to be available in both variety and quantity. The lack of 
availability and the limited variety of fruits and vegetables in the cafeteria were identified as barriers to consumption. When asked about the quantities of fruits and vegetables students are allowed to take, one child stated:

And they make, like, a limit on what you can get ... I mean, I think they should let us take more because not a lot of kids like fruits and vegetables so the fact that we want more should actually be kind of cool, and they should let us. (Female, School 1)

I don't like the milk here. I only like the milk my parents buy. (Female, School 3)

Desire for fresh local foods: Students expressed a strong preference for fresh foods, specifically, recently harvested produce from gardens and produce available at local farmers' markets. Students were probed for locations where fruits and vegetables were eaten outside of the home to determine students' knowledge of local food, and locations where fruits and vegetables are available to them. Primarily, students formulated their notions of healthy foods as being fresh, good tasting, and locally sourced, as indicated by their distrust surrounding processed foods. Additionally, children felt safer consuming produce from the school garden or local farmer's market because that produce was less processed. Responses from children included:

The garden's more healthier. You don't know what they do in the factory ... and the foods and stuff might be sprayed. (Male, School 1)

The salad bar is way more healthy and you can see the food being grown at the school. (Female, School 2)

Such statements expressed the children's views on the importance of knowing the origin of their food. A majority of the children identified the importance of having high quality, good-tasting foods served to them for school lunch. Many children expressed disappointment in the quality of entrée items served, describing these foods as greasy, cold, salty, soggy, and stale. The children identified entrée options as "disturbing" and "[it] bothers me a lot". One girl (School 1) objected, "We have to pay for our lunches, so we should get good things, not gross things."

\section{Healthfulness of Cafeteria Foods}

A major concern of students regarding the entrée items was the unhealthiness of the items served. When the students were asked what they would change about the entrée items, responses included less cheese, no grease, less salt on French fries, more rice, remove rotten items, and for the items to remain warm. One boy (School 2) remarked regarding the greasy food, "It's so much grease it's like a big puddle of grease on top of the pizza." Other students chose to eat more salad bar items in an attempt to offset some of the perceived unhealthiness of the entrée. One girl (School 2) remarked, "I go [to the salad bar] every time because like getting a side salad makes me feel better if I'm eating something bad for me." 
However, the children acknowledged the possible limitations of serving food to large numbers of students during the school year by comparing it to the summer school lunches. The children unanimously agreed the summer school lunches were better and healthier and reasoned that this was because, as one girl (School 1) said, "There's less days ... there is way less people ... so it's a lot easier to make good food."

Quality of milk at the cafeteria: The children were asked to describe their typical milk selection and consumption patterns. Taste was identified as a key determinant of milk consumption during school lunch. Many of the children expressed adverse feelings towards the milk served at school due to the fact that they viewed the milk offered as being quite different from the milk they consumed at home. The milk offered at school was further described as watery, warm, and weird tasting; the chocolate milk was said to taste even more disgusting than the white milk. However, the children felt that these characteristics might be due to the milk being served in cardboard cartons.

When students were asked about aspects of the school lunch they would like to see changed, the overwhelming response was with regard to having to purchase water. Students stated that the water from the drinking fountains is warm and that since they have a strong dislike of the milk served at school they often choose not to drink at all. Students also indicated that it was unfair for the school not to allow them to take several servings of fruits such as strawberries and kiwis.

\section{Impact of the HOTM program on students' knowledge and dietary behaviors:} Students expressed excitement about trying new fruits and vegetables, particularly when it came to eating new foods prepared in ways they weren't accustomed to. The HOTM program appeared to have had a positive impact on students' knowledge by promoting local fruits and vegetables. When students were asked to define the term "local food" a majority of the students were able to contribute a variety of descriptions of their notion of local, such as "organic", "grown in your town", "safer", and "foods you can get at the farmers' market". Students stated that the HOTM program gave them the opportunity to try new local foods, and this gave them insight into what kinds of foods they would prefer to have in their salad bar at lunch. One boy (School 1) remarked, "They [the HOTM program] also have, like, they have, like, different foods than at school that I would want in here because they taste better."

Students also provided positive feedback about the HOTM books and cooking demonstrations, and in that way demonstrated knowledge about produce and of how fruits and vegetables grow. Comments included:

Some of the foods that they have in the books are different from the school fruits, and that's, like, what we would want ... and you get to learn about the fruits and vegetables. (Male, School 1)

It's kind of cool because it tells you what they look like, what they are, how to identify them, um, how to tell this kind of fruit from this kind of fruit, how to tell 
International Journal of Child, Youth and Family Studies (2017) 8(3-4): 154-167

what a fruit is and what a vegetable is, just like different comparisons, and it's cool because it just helps, and it's kind of like one big scavenger hunt because, like, you'll be walking and you'll be like, "Oh, that's a potato. Oh, that's something." (Female, School 1)

\section{Peer and Family Influences on Food Behaviors}

Perceived "uncoolness" of fruits and vegetables among peers: When the students were asked about their peers' opinions about fruit and vegetable consumption, the overwhelming response was that fruits and vegetables were often viewed as being "uncool." Many students felt that their peers would not support them in choosing to consume fruits and vegetables at lunch. One student remarked:

A lot of the kids don't like vegetables or anything, like, at all, and so I think it's kind of cool when you hang out with somebody that likes the same things you do, even when it's as simple as fruits and vegetables. (Female, School 1)

This perception of "uncoolness" may be experienced more strongly among the older students, as is evidenced by one girl (School 1) stating, "Especially like sixth grade, not all people like vegetables because, you know, you have to be all cool and stuff."

Parental food preferences: Students noted that a few families were more likely to buy a variety of produce for the children while the majority purchased a more limited selection. Parental fruit and vegetable preferences impacted overall purchasing of produce for the entire family. Many students felt their families discouraged them from consuming fruits and vegetables; they viewed their parents not purchasing their produce preferences as a lack of support. Students expressed that they asked their parents to purchase different varieties of fruits and vegetables, some of which they had been exposed to at school, but parental tastes dictated whether the item was bought. One girl (School 2) said, "Then I wanted [my dad] to buy me [a pineapple] but then he hates pineapple, and he thinks I won't be able to eat a whole pineapple on my own."

Financial concerns among families: Due to economic concerns, some families were limited in their ability to purchase fresh fruits and vegetables, but financial means also influenced where purchasing was done. One boy (School 2) said, "I ask them to buy pineapple but they never do because they're not on sale." When asked specifically if their families purchased produce at a farmers' market, a girl (School 2) replied they did not because, "We don't have a lot of money for that. Well, like, my family can't really afford the more expensive, healthier veggies and fruits." Other students had similar economic concerns and stated that they couldn't afford fresh produce and consumed frozen vegetables.

Impact of the HOTM program on peers and families: The HOTM program provided students with the opportunity to taste and learn about a produce item each month in the classroom. The classroom activities appeared to have had a positive impact on students' overall attitudes 
toward consuming fruits and vegetables. Students expressed how they enjoyed the classroom cooking demonstrations because it gave them the opportunity to try new foods as a group. Regarding the tasting activity, students observed that it was an exciting experience, that the foods provided health benefits, and that it gave them knowledge they could share with friends and family. Furthermore, after each monthly cooking demonstration students were supplied with a recipe card to take home and share with their families. Students appreciated this aspect of the program because it provided them with a means to share with their parents what they had learned about fruits and vegetables. Comments included:

If [I] try something, and I like it, I'll be like, "Hey Mom, can we go get this. We tried it at school, and it was really good."... I think the HOTM kind of helps the parents because when we talk about the things that we like, it helps them, kind of know what we like. (Female, School 1)

\section{School Food Environment}

Communication between students and food service staff: Students did not feel they could openly express their concerns to those who provide the meals in the cafeteria. As a result, many felt the only recourse was either to eat less of the entrée or to skip the entrée entirely. There were divergent views from students about voicing their opinions to food service staff about their concerns in the cafeteria. There was an evident lack of communication between students and staff regarding food quality. The lack of communication was a result of the students being afraid and nervous to talk to the staff. After being asked if the students had ever voiced their concerns, students remarked:

We don't really, nobody really talks to the lunch ladies other than to tell them what they, what we want. So normally we tell, we just talk about it to the yard duties. (Female, School 1)

He's just, like, so uptight and scary. (Male, School 3)

Students also expressed concern over the way food was handled in the cafeteria. Many students reported that food service staff would not always wear gloves when handling food items. One boy (School 2) remarked, "I mean they don't put their gloves on but they don't wash their hands and I don't feel comfortable finding hairs and nails and the food is just disgusting."

Impact of the HOTM program on the school environment: The HOTM program had a positive influence on students' attitudes toward their schools and school staff. Some students appreciated the program because they felt it demonstrated the school's concern for their health and well-being by encouraging them to try a variety of fruits and vegetables. Students also noted that the HOTM program helped them better communicate with school staff regarding healthy eating. One girl (School 1) commented, "It's kind of cool that the school wants to help us just try new stuff." 
In summary, participants expressed a strong desire to receive more school support for healthy eating and wanted their voices to be heard. The HOTM program created a supportive environment that appeared to influence their food behaviors, perceptions of healthy eating among their peers and family members, and their attitudes toward their schools and the school staff.

\section{Discussion}

Multicomponent school-based nutrition programs are designed to improve the dietary behaviors of school-aged children. This qualitative study was intended to gain a better understanding of factors that affect dietary behaviors of children, as well as to qualitatively evaluate the impact of the HOTM program on knowledge, attitude, and behaviors. Findings reveal a wide range of factors influencing the food choices of school-aged children, including appearance, taste, availability, quality, and socioeconomic status. Findings also suggest positive implications for the use of school-based nutrition programs.

As reported by other studies, children made a distinction between healthy and unhealthy foods; fruits and vegetables were viewed as healthy whereas pizza and hamburgers were seen as unhealthy (Harrison \& Jackson, 2009; McKinley et al., 2005; Molaison, Connell, Stuff, Yadrick, \& Bogle, 2005; Neumark-Sztainer, Story, Perry, \& Casey, 1998; Noble, Corney, Eves, Kipps, \& Lumbers, 2000). Children expressed dissatisfaction with the food items available in the cafeteria, specifically the entrée items, in terms of lack of availability of healthy options. Consistent with findings from McKinley et al. (2005) and Chapman and Maclean (1993), meals eaten at home, in general, tended to be viewed as higher in nutritional quality than those eaten in the school environment. Negative comments were similar to findings from Power, Bindler, Goetz, and Daratha's (2009) study in which students stated that some entrée items such as the pizza and taco bowl were overly "greasy", which caused the students to skip lunch altogether. Consistent with Osowski, Göranzon, and Fjellström (2012), when the children were speaking negatively about the food in the cafeteria, the word most commonly used to describe the foods was "disgusting". Students also tended to associate the taste of food items, such as milk from cartons, with objects like cardboard and paper, and they perceived these tastes as different from what they consumed at home (Osowski et al., 2012).

This study documented students' perceptions of processed foods compared to local foods, a topic that to our knowledge has not been widely explored in elementary school students. Students expressed a strong preference for fresh foods, specifically recently harvested produce from school gardens and produce available at local farmers' markets. The current study revealed that students have negative perceptions of school cafeteria entrée items as primarily consisting of processed foods. This indicates that there may be a need to reform school lunch policy regarding entrée items.

A key environmental factor identified as a barrier to fruit and vegetable consumption in the cafeteria was the influence of peers. Specifically, when students were asked about the opinions of their peers regarding fruit and vegetable consumption, the overwhelming response was that these 
foods are viewed as being "uncool". This finding is similar to the results of other research in which students did not feel healthy eating was an attractive option (McKinley et al., 2005) and that friends were a major influence on students' eating patterns (Power et al., 2009).

Results from our study indicate that consumption of fruits and vegetables in the home may be directly related to the purchasing habits of parents and, therefore, to the availability of these foods at home. The reported influence of parents' purchasing habits on fruit and vegetable consumption in the home was also observed in other studies (Young, Fors, \& Hayes, 2004; Molaison et al., 2005). In the current study some students stated that their families buy a variety of fruits and vegetables, but the majority of students reported that parental preferences and economic concerns contributed to a lack of produce in the home.

The current study aimed to qualitatively evaluate the impact of the HOTM program on factors such as school food perceptions, peer and family influences, and school food environment. The HOTM program provided students with nutrition awareness. Specifically, the classroom cooking demonstrations allowed students to develop taste preferences for new foods and provided them with insight into additional produce options they might like that were available in the school cafeteria. This is evident through their strong preference for fresh fruits and vegetables and their increased desire for a wider variety of produce options in the cafeteria. This finding may prompt schools to offer more fruits and vegetables in the cafeteria and not restrict the amount students may take.

The most effective programs should intervene at multiple levels and so should include not only students and the school environment, but also parents (McKinley et al., 2005; Power et al., 2009). A lack of availability of produce items at home was a concern among study participants. HOTM provided students with recipe cards and parent newsletters to share with their families; the recipe cards did appear to have a positive influence. Future interventions aimed at school-aged children should incorporate a stronger parental component by identifying other mechanisms for reaching parents, such as family tasting events and nutrition-related homework activities.

Similar to findings from Potter and colleagues (2011), students expressed appreciation for the HOTM program because they felt that, through encouraging them to try new fruits and vegetables, the school was demonstrating concern for their health and well-being. Students felt that the schools should offer more healthy food options as part of the school lunch program; specifically, produce items they had tasted through the program. To obtain optimal impact, such programs should incorporate HOTM produce items into the cafeteria as well as generally making food in the cafeteria more appealing and more produce available.

The current study has several limitations. The number of study participants was small and the study was conducted in one rural area in northern California. As a result, study findings may not reflect the larger population of elementary school children in the United States. In addition, 
the current study employed a qualitative method; an experimental study needs to be conducted to further assess or confirm the effectiveness of the HOTM program.

\section{Conclusions}

The findings from this study indicate that changes in school nutrition policy and interventions such as the HOTM program effectively complement each other for student dietary behavioral changes. School-based experiential nutrition interventions such as the HOTM nutrition program provide students with a positive and supportive environment that may influence their dietary behaviors, peer and family perceptions of healthy eating, and attitudes toward their schools and the school staff. On the other hand, some challenges, such as the lack of availability and the unattractiveness of healthy foods in the school cafeteria, need to be addressed at the policy level through nutrition legislation reform. The current study indicates that such policy changes can become more effective when combined with experiential nutrition interventions such as classroom tasting activities, cooking demonstrations, and nutrition education. Our study participants' strong preference for locally grown fresh fruits and vegetables and their desire for more produce options in the cafeteria appear to be largely due to their participation in the HOTM program. Thus, increasing the availability of fruits and vegetables through school food policy changes alone may not be effective in improving children's fruit and vegetable consumption in school.

When developing nutrition intervention programs for school-aged children it is critical to address parental and environmental influences that discourage students from practicing healthy eating habits. Parents' unwillingness to buy certain fruits and vegetables due to their own taste preferences warrant the inclusion of parental education in nutrition intervention programs.

Future research should focus on exploring effective and synergistic ways of implementing both nutrition legislation reform and nutrition intervention programs. Our study participants' strong desire to have their voices heard for a better school food environment suggests youth engagement for both nutrition policy and education interventions is key to achieving successful dietary behavioral changes among students. Additionally, more research is needed to further investigate the differences between the home and the school environments regarding food availability and choices. Overall, a multicomponent school-based nutrition intervention program can be a useful approach to improve dietary behaviors among elementary school students.

\section{Acknowledgements}

The Harvest of the Month study was funded by Federal Financial Participation reimbursement funding through the United States Department of Agriculture Supplemental Nutrition Assistance Program (SNAP) via a contract with the California Department of Public Health's Nutrition Education and Obesity Prevention Branch. The authors wish to thank the staff and student interns at the California State University, Chico and our study participants for their support. 
International Journal of Child, Youth and Family Studies (2017) 8(3-4): 154-167

\section{References}

Béhague, D. P., Gonçalves, H., \& Victora, C. G. (2008). Anthropology and epidemiology. Learning epistemological lessons through a collaborative venture. Cien Saude Colet, 13(6), 1701-1710. doi:10.1590/S1413-81232008000600002

California Department of Public Health. (2016). SNAP-Ed toolkit: Harvest of the month [Webpage]. Retrieved from https://snapedtoolkit.org/interventions/programs/harvest-of-themonth-hotm/\#Evidence_Summary

Chapman, G., \& Maclean, H. (1993). "Junk foods" and "Healthy food": Meanings of food in adolescent women's culture. Journal of Nutrition Education, 25, 108-113. doi:10.1016/S0022-3182(12)80566-8

Chen, Q., Goto, K., Wolff, C., Bianco-Simeral, S., Gruneisen, K., \& Gray, K. (2014). Cooking up diversity: impact of a multi-component, multi-cultural, experiential intervention on food and cooking behaviors among K-2 students from low-income ethnically diverse families. Appetite, 80, 114-22. doi:10.1016/j.appet.2014.05.009

Clark, M. A., \& Fox, M. K. (2009). Nutritional quality of the diets of US public school children and the role of the school meal programs. Journal of the American Dietetic Association, 109, S44-S56. doi:10.1016/j.jada.2008.10.060

Goto, K., Wolff, C., Frigaard, M. \& Bianco-Simeral, S. (2012). The impact of a multicomponent school-based program on fruit and vegetable selection from school salad bars among K-6 grade students. Journal of Nutrition Education and Behavior, 44, S75-76. doi:10.1016/j.jneb.2012.03.177

Graham, H., Feenstra, G., Evans, A. \& Zidenberg-Cherr, S. (2004). Davis school program supports life-long healthy eating habits in children. California Agriculture, 58(4), 200-205.

Harrison, M., \& Jackson, L. A. (2009). Meanings that youth associate with healthy and unhealthy food. Canadian Journal of Dietetic Practice and Research, 70, 6-12. doi: $10.3148 / 70.1 .2009 .6$

Heim, S., Stang, J., \& Ireland, M. (2009). A garden pilot project enhances fruit and vegetable consumption among children. Journal Academy of Nutrition and Dietetics, 109, 1220-1226. doi:10.1016/j.jada.2009.04.009

Hussar, W. J., \& Bailey, T. M. (2009). Projections of Education Statistics to 2018 (NCES 200906). Washington, DC: National Center for Education Statistics, Institute of Education Sciences, U.S. Department of Education. Retrieved from https://nces.ed.gov/pubs2009/2009062.pdf 
International Journal of Child, Youth and Family Studies (2017) 8(3-4): 154-167

McLeroy, K. R., Bibeau, D., Steckler, A., \& Glanz, K. (1988). An ecological perspective on health promotion programs. Health Education Quartery, 15(4), 351-377. doi:10.1177/109019818801500401

McKinley, M. C., Lowis, C., Robson, P. J., Wallace, J. M. W., Morrissey, M., Moran, A., \& Livingstone, M. B. E. (2005). It's good to talk: Children's views on food and nutrition. European Journal of Clinical Nutrition, 59, 542-551. doi:10.1038/sj.ejcn.1602113

Mills, A. J., Durepos, G., \& Wiebe, E. (Eds). (2010). Encyclopedia of Case Study Research. Thousand Oaks, CA: Sage.

Molaison, E. F., Connell, C. L., Stuff, J. E., Yadrick, M. K., \& Bogle, M. (2005). Influences on fruit and vegetable consumption by low-income black adolescents. Journal of Nutrition Education and Behavior, 37, 246-251. doi:10.1016/S1499-4046(06)60279-0

Neumark-Sztainer, D., Story, M., Perry, C., \& Casey, M. A. (1998). Factors influencing food choices of adolescents: findings from focus-group discussions with adolescents. Journal of the American Dietetic Association, 99, 929-937. doi:10.1016/S0002-8223(99)00222-9

Nicklas, T. A., Johnson, C. C., Myers, L., Farris, R. P., \& Cunningham, A. (1998.) Outcomes of a high school program to increase fruit and vegetable consumption: Gimme 5 - A fresh nutrition concept for students. Journal of School Health, 68, 248-253. doi:10.1111/j.1746$\underline{1561.1998 . t b 06348 . x}$

Noble, C., Corney, M., Eves, A., Kipps, M., \& Lumbers, M. (2000). Food choice and school meals: Primary schoolchildren's perceptions of the healthiness of foods and nutritional implications of food choices. International Journal of Hospitality Management, 19, 413432. doi:10.1016/S0278-4319(00)00038-4

Ng, M., Fleming, T., Robinson, M., Thomson, B., Graetz, N., Margono, C., ... Gakidou, E. (2014). Global, regional, and national prevalence of overweight and obesity in children and adults during 1980-2013: A systematic analysis for the Global Burden of Disease Study 2013. Lancet, 384, 766-781. doi:10.1016/S0140-6736(14)60460-8

Ogden, C. L., Carroll, M. D., Fryar, C. D., \& Flegal, K. M (2015). Prevalence of obesity among adults and youth: United States, 2011-2014. [NCHS Data Brief. No. 219]. Retrieved from https://www.cdc.gov/nchs/data/databriefs/db219.pdf

Osowski, C. P., Göranzon, H., \& Fjellström, C. (2012). Children's understanding of food and meals in the foodscape at school. International Journal of Consumer Studies, 36, 54-60. doi:10.1111/j.1470-6431.2011.01003.x 
International Journal of Child, Youth and Family Studies (2017) 8(3-4): 154-167

Pan, L., Blanck, H. M., Sherry, B., Dalenius, K., \& Grummer-Strawn, L. M. (2012). Trends in the prevalence of extreme obesity among US preschool-aged children living in low-income families, 1998-2010. Journal of the American Medical Association, 308, 2563-2565. doi:10.1001/jama.2012.108099

Pérez-Rodrigo, C., \& Aranceta, J. (2001). School-based nutrition education: Lessons learned and new perspectives. Public Health Nutrition, 4, 131-139. doi:10.1079/PHN2000108

Perry, C. L., Bishop, D. B., Taylor, G., Murray, D. M., Mays, R. W., Dudovitz, B. S., Smyth, M., \& Story, M. (1998). Changing fruit and vegetable consumption among children: The 5-aday power plus program in St. Paul, Minnesota. American Journal of Public Health, 88(4), 603-609.

Pilnick, A., \& Swift, J. A. (2011). Qualitative research in nutrition and dietetics: Assessing quality. Journal of Human Nutrition and Dietetics, 24, 209-214. doi:10.1111/j.1365277X.2010.01120.X

Potter, S. C., Schneider, D., Coyle, K. K., May, G., Robin, L., \& Seymour, J. (2011). What works? Process evaluation of a school-based fruit and vegetable distribution program in Mississippi. Journal of School Health, 81, 202-211. doi:10.1111/j.1746-1561.2010.00580.x

Power, T. G., Bindler, R. C., Goetz, S., \& Daratha, K. B. (2009). Obesity prevention in early adolescence: Student, parent, and teacher views. Journal of School Health, 80, 13-19. doi:10.1111/j.1746-1561.2009.00461.x

Shannon, C., Story, M., Fulkerson, J. A., \& French, S. A. (2002). Factors in the school cafeteria influencing food choices by high school students. Journal of School Health, 72, 229-234. doi:10.1111/j.1746-1561.2002.tb07335.x

Story, M., Kaphingst, K. M., Robinson-O'Brien, R., \& Glanz, K. (2008). Creating healthy food and eating environments: Policy and environmental approaches. Annual Review in Public Health, 29(1), 253-272. doi:10.1146/annurev.publhealth.29.020907.090926

Young, E. M., Fors, S. W., \& Hayes, D. M. (2004). Associations between perceived parent behaviors and middle school student fruit and vegetable consumption. Journal of Nutrition Education and Behavior, 36, 2-12. doi:10.1016/S1499-4046(06)60122-X 